\title{
OÚRICUR'
}

\section{O IMPACTO SOCIAL CAUSADO PELOS PROGRAMAS ESPORTIVOS NO MUNICÍPIO DE PAULO AFONSO-BA}

\author{
Rafael Rodrigues dos SANTOS ${ }^{1 *}$; André Luiz PETROLINI ${ }^{2}$ \\ $1^{*}$ Estudante do curso de Gestão Pública da Universidade Vale do São Francisco - UNIVASF, \\ Paulo Afonso-BA. *Autor Correspondente. E-mail: rafasantos_123@hotmail.com \\ ${ }^{2}$ Mestre em Educação Física (UNIVASF). Técnico de Anatomia e Necropsia da Universidade \\ Federal do Vale do São Francisco, Brasil. E-mail: andre.petrolini@univasf.edu.br \\ Recebido: 03.03.2021 Aceito: 01.06.2021
}

\begin{abstract}
Resumo: Apresentando-se como princípio essencial na democratização, por meio dos Projetos Sociais Esportivos, é evidenciado a importância do esporte na vida das pessoas, sobretudo para crianças e adolescentes. Através do esporte faz-se possível a integração social, o resgate de valores, o estabelecimento de regras, a convivência social, entre muitas outras coisas fundamentais para o desenvolvimento integral do individuo. De tal modo, os projetos sociais esportivos priorizam as classes menos privilegiadas, que consequentemente possuem maiores chances de estarem em situações de risco social por muitas vezes encontrarem-se à margem da sociedade. Assim, a presente pesquisa tem como objetivo analisar como os projetos sociais esportivos beneficiam o usuário do município de Paulo Afonso-BA, verificando dessa forma, os impactos ocasionados por eles.
\end{abstract}

Palavras-chave: Projetos Sociais Esportivos. Esporte. Benefícios.

\section{THE SOCIAL IMPACT CAUSED BY THE SPORTS PROGRAMS IN THE MUNICIPALITY OF PAULO AFONSO-BA}

Abstract: Presenting itself as an essential principle in democratization, through the Social Sports Projects, the importance of sport in people's lives, especially for children and adolescents, is evidenced. Through sport, social integration, the recovery of values, the establishment of rules, social coexistence, among many other things that are fundamental for the integral development of the individual, are possible. Thus, social sports projects prioritize the less privileged classes, which consequently have a greater chance of being in situations of social risk because they often find themselves on the margins of society. Thus, the present research aims to analyze how social sports projects benefit the user of the city of Paulo Afonso-BA, verifying, in this way, the impacts caused by them.

Keywords: Sports Social Projects. Sport. Benefits.

\section{EL IMPACTO SOCIAL DE LOS PROGRAMAS DEPORTIVOS EN EL MUNICIPIO DE PAULO AFONSO-BA}

Resumen: Presentándose como un principio fundamental en la democratización, a través de los Proyectos Sociodeportivos, se destaca la importancia del deporte en la vida de las personas, especialmente de la niñez y la adolescencia. A través del deporte se hace posible la integración

Revista Ouricuri, Juazeiro, Bahia, v.11, n.1. p.103-110. jan./jul., 2021. http://www.revistas.uneb.br/index.php/ouricuri | ISSN 2317-0131 
social, la recuperación de valores, el establecimiento de reglas, la convivencia social, entre muchas otras cosas imprescindibles para el desarrollo integral del individuo. De esta manera, los proyectos sociales deportivos priorizan las clases menos privilegiadas, que en consecuencia tienen mayores posibilidades de encontrarse en situaciones de riesgo social porque muchas veces se encuentran al margen de la sociedad. Así, esta investigación tiene como objetivo analizar cómo los proyectos sociodeportivos benefician al usuario en la ciudad de Paulo Afonso-BA, verificando así los impactos ocasionados por los mismos.

Palabras clave: Proyectos sociodeportivos. Deporte. Beneficios.

\section{INTRODUÇÃO}

Paulo Afonso, município localizado na região Nordeste do estado da Bahia e pertencente à micro região homogênea do sertão de Paulo Afonso foi emancipado em 28 de julho de 1958, ocupando uma área territorial de 1.700,40 quilômetros quadrados, a qual possui uma população estimada em 120706 , de acordo com estimativas do Instituto Brasileiro de Geografia e Estatística (IBGE) em 2017.

Através da Secretaria Municipal de Desenvolvimento Social e da Secretaria Municipal de Cultura e Esportes, o município de Paulo Afonso-BA oferece programas sociais esportivos no intuito de proporcionar o desenvolvimento de potencialidades das famílias e reintegração social, relacionando de tal modo os programas oferecidos com impacto social causado.

O esporte, como comumente vem sendo apresentado, prioriza e oportuniza àqueles que são mais hábeis, deixando de lado ou excluindo os de menores potenciais. De acordo com Marino (2007) os projetos sociais têm como foco principal a inclusão social e o desenvolvimento da cidadania de seus participantes. Os que são voltados ao esporte não podem ser diferentes, pois tem seu papel no processo de socialização, onde a mesma é uma forma de controle social, pela adaptação do praticante aos valores e normas dominantes como condição trazida para a funcionalidade e desenvolvimento da sociedade. Deste modo, a socialização é um meio de integração e inclusão que através do esporte, busca oportunizar ao indivíduo o conhecimento e numerosos benefícios que o mesmo proporciona.

Dessa forma, diante a esta questão, a problemática da pesquisa pautou-se na seguinte pergunta: como os programas sociais oferecidos pelo município de Paulo Afonso-BA são avaliados pela população?

Assim, o objetivo geral da pesquisa buscou analisar como acontece o processo de inclusão nos projetos sociais esportivos, baseado em verificar como as práticas esportivas educacionais têm estimulando a população a manter uma interação efetiva que contribua para o seu desenvolvimento integral; e analisar como o esporte é concebido como meio para educação e a vida, promovendo assim o ensino da convivência em grupo, o conhecimento das capacidades, a tomada de decisão e a busca por soluções dos problemas. 


\section{FUNDAMENTAÇÃO TEÓRICA}

A sociedade se constitui como uma engrenagem na vivência nas relações sociais, e com as pessoas, sendo que essas engrenagens vão se moldando de acordo com as características que a economia vai formando e daí surgem novas necessidades de abordagens capazes de atender um contexto vigente.

De acordo com a bibliografia pesquisada, os projetos sociais caracterizam-se como uma alternativa as necessidades sociais de pessoas com baixa renda que estão inseridos no que se conhece como terceiro setor. Assim, "os projetos sociais começaram a surgir no Brasil a partir das primeiras décadas do século XX (Isayama; Linhales, 2008)" e, no século XXI, configuram-se como uma prática cultural legitimada pela sociedade, pelo Estado e pelo mercado.

Desde seu surgimento, os projetos sociais passaram por diferentes concepções e, segundo Zaluar (1994), contribuíram para complementar os processos educativos formais, ou seja, a escola, de maneira especial às classes menos favorecidas. Hoje, tais projetos surgem com a justificativa de oferecer à população em vulnerabilidade social uma oportunidade de ocupação do tempo livre. De tal modo, vale ressaltar que a vulnerabilidade social está associada a uma combinação de fatores que podem produzir uma deterioração no nível de bem-estar de pessoas, famílias ou comunidades, em consequência de sua exposição a determinados riscos.

Dentre as ofertas nos projetos sociais, o esporte tem sido um conteúdo atrativo para crianças e adolescentes, considerado com um fenômeno sociocultural que exerce forte influência na vida humana, sendo um dos fenômenos sociais mais importantes do século XXI (Sadi, 2010).

Em relação as políticas públicas destinadas ao esporte, Steinhilber (2008) mencionam que é essencial que tanto as Políticas, os Planos e Programas estejam nitidamente identificados e os recursos públicos colocados conforme com as reais necessidades sociais e não de projeção pessoal, para que dessa forma, possam ser compreendidos por todos, transparentes, e assim permitam seu acompanhamento de maneira simplificada.

Tendo em vista a representatividade do esporte em nossa sociedade e levando em consideração que os significados atribuídos a sua prática, bem como as transformações sofridas por tal fenômeno, devemos nos questionar sobre que praticantes se formarão por meio da prática esportiva (SADI, 2010), em especial nos projetos sócio esportivos, que tem por objetivo a formação cidadã pelo esporte.

O esporte é analisado como prática em que são seguidas regras de maneira oficial e competitiva, formadas em federações regionais, nacionais e internacionais que regulamentam a atuação amadora e a profissional, envolvendo as condições espaciais e de equipamentos 
sofisticados como campos, piscinas, bicicletas, pistas, ringues, ginásios entre outros (Mascarenhas, 2010).

Atualmente, o Brasil apresenta inúmeros projetos sociais, patrocinados por instituições governamentais, empresas privadas, organizações não-governamentais (ONGs), organizações da sociedade civil (OSCIPs), as quais buscam inserir crianças e adolescentes, especialmente os mais vulneráveis e que estejam em situação de risco social, desempenhado assim um importante papel na sociedade, os quais assumem papeis importantes de acesso aos direitos para este público, como por exemplo, educação, lazer, alimentação dentre outros (Machado; Moreno, 2011).

Diversos projetos sociais têm em vista contemplar direitos de desenvolvimento pessoal e social, integridade física, psicológica e moral através da redução da inatividade e, portanto, a redução da vulnerabilidade social ocasionando assim, estação para aprendizagens, as quais são essenciais para o trabalho em grupo, discussão de normas da sociedade e aspectos ideais para o convívio social.

Vale ressaltar que, além dos projetos sociais, existem os projetos esportivos, que embora muitas vezes são desenvolvidos em comunidades ou em locais de vulnerabilidade social não possuem suas premissas enraizadas nas regras dos projetos sociais, uma vez que, os projetos esportivos têm como um dos principais alvos a detecção de talentos esportivos ou mesmo o desenvolvimento ou massificação de uma determinada modalidade esportiva (Machado; Moreno, 2011).

Ainda conforme os autores, em relação à detecção de talentos, o trabalho não é aberto a todos, tornando- o assim um trabalho excludente. Todavia, se trabalhado de maneira a contemplar a iniciação ou mesmo à manutenção o trabalho passa a ser mais integrativo e contemplando um público maior. É válido destacar também que existem projetos que beneficiam uma associação entre as duas frentes, tanto a de projeto social, quanto o projeto esportivo, a qual é chamada projeto sócio esportivo, se divergindo dos projetos esportivos por empregar o esporte não como uma finalidade, mas sim, como um modo de inclusão social.

Deste modo, o esporte beneficia a atividade coletiva, o qual desenvolve a consciência comunitária, estimulando a identidade e quando calcado nos valores, normas, princípios e boas condutas cidadã que são defendidas pelo mesmo, este se modifica em uma excelente ferramenta para ser trabalhada nos projetos sociais.

\section{MÉTODOS}

Os procedimentos metodológicos adotados na busca para atingir os objetivos deste estudo foram divididos no delineamento da pesquisa; tipo de estudo; instrumento de pesquisa e coleta de dados, sendo a pesquisa caracterizada como descritiva e exploratória. 
A pesquisa descritiva busca analisar um fato para delineá-lo de maneira absoluta ou distingui-lo de outro. A pesquisa descritiva demanda do investigador uma série de informações sobre o que anseia pesquisar. Conforme Triviños (1987, p. 112), os estudos descritivos podem ser recriminados porque pode ter uma definição correta dos acontecimentos e dos fatos, fugindo estes da probabilidade de averiguação por meio da observação.

Todavia, a pesquisa exploratória usa artifícios extensos e volúveis, tais como, levantamento de fontes secundárias, levantamentos de experiências, estudo de casos selecionados e observação informal, buscando descobrir se existe ou não um fato, tendo em vista proporcionar maior intimidade com o problema com desígnio de torná-lo explicito ou de estabelecer suposições (Matias, 2007).

A pesquisa primeiramente procedeu-se em duas etapas. A primeira etapa foi através de pesquisa bibliográfica para conhecimento do tema, em dissertações, artigos científicos, livros e internet. A pesquisa bibliográfica é organizada a partir de material já publicado, construído principalmente por meio de livros, artigos, periódicos e atualmente materiais disponibilizados na internet (Matias, 2007).

$\mathrm{Na}$ segunda etapa, foi realizada uma entrevista com o secretario municipal de esportes do município de Paulo Afonso, para o levantamento de informações a respeito do trabalho esportivo social. O instrumento de pesquisa utilizado foi um questionário que de acordo com Lakatos, (2003, p. 195) "consiste no desenvolvimento de precisão, focalização e validade de certo ato social como a conversação", tendo como objetivo principal a obtenção de informações do entrevistado, sobre determinado assunto ou problema.

\section{RESULTADOS E DISCUSSÃo}

De acordo com a entrevista realizada com o secretário de Esportes do município, a cidade de Paulo Afonso-BA dispõe de diversos projetos sociais voltados para a área esportiva, os quais seguem abaixo na tabela 1:

Tabela 1: Projetos Sociais Esportivos - Prefeitura Municipal de Paulo Afonso-BA.

\begin{tabular}{c|c|c}
\hline $\begin{array}{c}\text { PROJETO } \\
\text { ESPORTIVO }\end{array}$ & MODALIDADE & FAIXA ETÁRIA \\
\hline Esporte Educar & $\begin{array}{c}\text { Futsal, jiu-jitsu e } \\
\text { capoeira }\end{array}$ & 7 a 14 anos \\
\hline Liga BTN de Futsal & $\begin{array}{c}\text { Futsal nas categorias } \\
\text { Sub 9, Sub 11, Sub 13, } \\
\text { Sub 15, Sub 17 }\end{array}$ & Adulto Masculino \\
\hline $\begin{array}{c}\text { Liga Área Rural de } \\
\text { Futsal }\end{array}$ & Futsal & $\begin{array}{c}\text { Adulto Masculino e } \\
\text { Feminino }\end{array}$ \\
\hline Zumba e Aeróbica & Dança e aeróbica & Jovens e adultos \\
\hline
\end{tabular}

Revista Ouricuri, Juazeiro, Bahia, v.11, n.1. p.103-110. jan./jul., 2021. http://www.revistas.uneb.br/index.php/ouricuri | ISSN 2317-0131 


\begin{tabular}{c|c|c}
\hline Muay-Thai & Muay-Thai & Jovens e adultos \\
\hline Vida Saudável & Exercícios físicos & Idosos \\
\hline \multicolumn{2}{c|}{ Fonte: Prefeitura Municipal de Paulo Afonso (2018). }
\end{tabular}

Em relação aos objetivos que os projetos sociais esportivos apresentam aos seus usuários, segundo o secretario de esportes, todos os projetos buscam acima de tudo a inclusão social e o desenvolvimento da cidadania de seus participantes.

A maior parte dos projetos sociais esportivos está voltada às crianças e jovens, classificados algumas vezes como em "situação de risco social" ou em "situação de vulnerabilidade social" e objetivam ocupar o tempo livre dos mesmos. Os projetos podem ser exclusivos da área esportiva ou podem também ofertar atividades profissionalizantes e complementares à escolarização formal (GUEDES et al., 2006).

De acordo com o secretario de esportes, a inclusão dos usuários aos projetos sociais esportivos acontece por meio de cadastros destinados ao publico participante, conforme a faixa etária destinada a cada projeto. Vale ressaltar ainda que para a inserção nos mesmos, os participantes precisam ser estudantes da esfera municipal e/ou estadual.

Em relação ao projeto vida saudável, ele é ofertado pela secretaria municipal de Desenvolvimento Social, destinado ao público idoso, com o objetivo de oferecer exercícios físicos gratuitamente, recebendo todo o acompanhamento necessário dos monitores disponibilizados pela Prefeitura.

Além dos exercícios físicos, o grupo participa de atividades lúdicas através de passeios, cafés da manhã e piquenique, além de palestras sobre saúde. Através do Vida Saudável, é proporcionado aos idosos uma melhoria considerável na qualidade de vida, com o aumento da resistência física, bem como a vivência de momentos de lazer, com as atividades lúdicas. As atividades físicas são ofertadas na Praça da Igreja Nossa Senhora de Fátima, no Clube Operário Paulo Afonso (COPA), nos bairros Centenário, Moxotó Bahia e na Ceasa, contemplando os moradores do Bairro Tancredo Neves.

Dessa forma, por meio dos projetos sociais esportivos, é possível favorecer aos seus usuários a atividade coletiva, o desenvolvimento da consciência comunitária, estimulando de tal modo a identidade e quando calcado nos valores, normas, princípios e boas condutas cidadã que são defendidas pelo esporte este se transforma em uma excelente ferramenta para ser trabalhada nos projetos sociais.

\section{CONSIDERAÇÕES FINAIS}

De acordo com a realização da presente pesquisa no município de Paulo Afonso-BA, foi possível verificar que os programas esportivos sociais, apresentam benefícios sociais, culturais e esportivos, uma vez que preenche o tempo livre, oferece esporte a uma respectiva demanda, 
como também favorece a inclusão de usuários econômica e socialmente vulneráveis. De tal modo, vale ressaltar que o esporte é uma maneira enriquecedora para todos que o praticam, levando informações, conhecimentos e aprendizagem.

De tal modo, pode-se mencionar que os Projetos Sociais interferem no desenvolvimento integral da promoção da saúde e da qualidade de vida da população, pois atualmente vêm-se procurando por programas efetivos, bem estruturados, com planejamento de recursos financeiros e capital humano apropriado, além de tempo suficiente para a sua implantação e coleta de resultados. Assim, é notório que tais programas promoverão o desenvolvimento humano, especialmente as crianças em idade escolar, incentivando uma transformação de comportamento.

Portanto, conclui-se que o município de Paulo Afonso-BA, apresenta um quadro esportivo com diversas modalidades, as quais abrangem todos os públicos, ou seja, desde a criança até o idoso, proporcionando assim oportunidades de inclusão por meio do Esporte e Lazer. Vale ressaltar que a efetividade dos projetos apresentados pela prefeitura municipal, são de grande sucesso na área esportiva, avaliando que todos os Programas Públicos devem ser precedidas de compreensão das necessidades locais.

\section{REFERÊNCIAS}

Baptista, M. T. (et. al.) Influência da Escola de educação física do Exército na origem do currículo da educação física no Brasil.www.efdeportes.com. Revista Digital. Buenos Aires. Año 9 n. 62 julio. 2003 6p.

Barroso, A. L. R.; Darido, S. C. A pedagogia dos esportes e as dimensões dos conteúdos: conceitual e atitudinal. Rev. Bras. Educ. Fís. Esporte, São Paulo, v. 26, n. 2, p. 283-300. abr/jun. 2009.

Bracht, V. Educação Física e aprendizagem social. Porto Alegre: Editora Magister, $2^{\mathfrak{a}}$ edição, 1997.

Bennis, W.Líderes: Estratégias para assumir a verdadeira liderança. São Paulo, Harbra, 1988.

Betti, I. C. R. Esporte na escola: mas é só isso professor? Motriz, v. 1, n.1, p. 25-31, jun. 1999.

Brasil Secretaria de Educação Fundamental. Parâmetros curriculares nacionais; educação física. Secretaria de Educação Fundamental. Brasília: MEC/SEF. 1997. 96p.

Carvalho, R. E. Removendo barreiras para a aprendizagem: educação inclusiva. 9. ed. Porto Alegre: Mediação, 2009.

Cesarino Júnior, Antônio Ferreira. Direito social brasileiro. 5. ed. Rio de Janeiro: Freitas Bastos, 1963.

Delors, J. Educação: um tesouro a descobrir. Relatório para a Unesco da Comissão Internacional sobre a Educação para o Século XXI. 2001. 
GUedes, S. L. et al. Projetos sociais esportivos: notas de pesquisa. 2006. In: ENCONTRO REGIONAL DE HISTÓRIA, 12, 2006, Niterói. Anais... Rio de Janeiro: ANPUH, 2006. p. 92-92.

Gil, A. C. Como elaborar projetos de pesquisa. 4. ed. São Paulo: Atlas, 2002.

Como elaborar projetos de pesquisa. 4. ed. São Paulo: Atlas, 2008.

Houaiss, A. Dicionário eletrônico. Rio de Janeiro, Objetiva, 2001, CD-rom.

Isayama, H. F.; Linhales, M. A. (Org.). Avaliação de políticas e políticas de avaliação: questões para o esporte e o lazer. Belo Horizonte: Editora UFMG, 2008.

Stiel Júnior, O. A humanização da escola e a valorização da diversidade em sala de aula. Vol. 01, p. 11, 2014.

Lampoglia, M. A. Liderança e Motivação. Fev 2008.

Lampoglia, M. A. O valor da Inteligência Emocional nas organizações inteligentes. Abril 2009.

Lefevre, J. The value of diversity: a justification of affirmative action. Journal of Social Philosophy, v. 34, n. 1, p. 125-134, 2003.

Leonardi, T. J.; Galatti, L. R.; Paes, R. R.: Pedadogia do esporte. O processo de ensino, vivencia e aprendizagem dos jogos esportivos coletivos e sua relação com a formação integral do individuo. In: II Congresso Internacional de Deportes de Equipo, 2009, A Coruña. II Congresso Deportes de Equipo, 2009.

Mascarenhas, F. O pedaço sitiado: cidade, cultura e lazer em tempos de globalização. Revista Brasileira de Ciências do Esporte. Campinas, v. 24, n. 3, p. 121-143, mai. 2010.

Moreno, R. M.; Machado, A. A. Re- significando o esporte na educação física escolar: uma perspectiva crítica. Movimento \& Percepção, Espírito Santo de Pinhal, SP, v.6, n.8, jan./jun. 2011.

Paes, R. R., Balbino, H. F. A pedagogia do esporte e o jogos coletivos. Cap. 5, p. 73 - 83. In: DE ROSE, D. et al. Esporte na Infância e Adolescência: uma abordagem multidisciplinar. 2ª Ed. Porto Alegre: Artmed, 2001.

Sabino, D. A importância de ser emocionalmente Inteligente. 2008.

Sachs, I. Caminhos para o desenvolvimento sustentável. Organização: Paula Yone Stroh. Rio de Janeiro: Garamond, 2000.

Sadi, R. S. Pedagogia do esporte: descobrindo novos caminhos. Ícone, São Paulo, 2010.

Smith, D. H. Four Sectors or Five? Retaining the Member-Benefit Sector. Nonprofit and Voluntary Sector Quarterly. V. 20 N. 2, Summer 1991, pp.137-50.

Souza, A. Autoconhecimento. Abril 2005.

Trivinos, A. N. S. Introdução à pesquisa em Ciências Socais: a pesquisa qualitativa em educação. São Paulo: Atlas, 1987. 
Wagner III, J. A.; Hollenbeck, J.R. Comportamento organizacional: criando vantagem competitiva. Tradução: Cid Knipel Moreira. São Paulo: Saraiva, 2003.

Revista Ouricuri, Juazeiro, Bahia, v.11, n.1. p.103-110. jan./jul., 2021.

http://www.revistas.uneb.br/index.php/ouricuri | ISSN 2317-0131 